\title{
Synthesis and analysis of single shaped reflector antennas
}

\author{
Viskum, H. H.
}

Published in:

Antennas and Propagation Society International Symposium,

Publication date:

1986

Document Version

Publisher's PDF, also known as Version of record

Link back to DTU Orbit

Citation (APA):

Viskum, H. H. (1986). Synthesis and analysis of single shaped reflector antennas. In Antennas and Propagation Society International Symposium, (pp. 651-654). IEEE.

\section{General rights}

Copyright and moral rights for the publications made accessible in the public portal are retained by the authors and/or other copyright owners and it is a condition of accessing publications that users recognise and abide by the legal requirements associated with these rights.

- Users may download and print one copy of any publication from the public portal for the purpose of private study or research.

- You may not further distribute the material or use it for any profit-making activity or commercial gain

- You may freely distribute the URL identifying the publication in the public portal

If you believe that this document breaches copyright please contact us providing details, and we will remove access to the work immediately and investigate your claim 


\author{
H.-H. Viskum \\ Electromagnetics Institute \\ Technical University of Denmark \\ DK-2800 Lyngby, Denmark
}

Introduction. Although geometrical optics $(\mathrm{GO})$ is an asymptotic theory describing electromagnetic fields of infinitely high frequencies only, it has for several years constituted the foundation for synthesis of reflector antennas. While dual reflectors are usually shaped to produce a certain aperture distribution leading to a pencil beam type pattern with high gain or low side lobes, etc., single reflectors may be synthesised to generate shaped beams by using the GO directly in the far field. In either of the cases, any design must necessarily be verified by a diffraction analysis, because of the GO assumption made in the synthesis.

In this paper we will demonstrate a numerical method for solving the synthesis problem for single reflector antennas. The technique has been found to be superior to what has previously been applied, in particular because it returns the solution on a form which lends itself easily to diffraction analysis. This is accomplished by solving Westcott's synthesis problem using a collocation method and an expansion of the reflector surface in bicubic spline functions.

The theory will be resumed very briefly, and we will then present some results from applying the developed synthesis and analysis programs to a particular configuration, a reflector shaped to provide full earth coverage from a low orbitting satellite.

Formulation of the synthesis. As stated previously, the synthesis part of this study is based upon the work of Westcott (1983). To formulate the problem we consider the reflector shown in fig. 1 , illuminated by a feed located at the centre of the coordinate system. The half angle subtended by the reflector at the feed is $\theta_{c}$. Given the feed power density pattern $f(\theta, \phi)$, we require the reflector to transform this pattern into a far-field pattern with a power density distribution $\mathbf{G}(\theta, \phi)$ inside the far-field cone of half angle $\theta_{\boldsymbol{f}}$. Westcott showed that by using an appropriate parametrization of the reflectoor surface one can derive a highly non-linear boundary value problem, the solution of which governs the reflector surface. He also showed how the non-linear problem could be linearized and solved by repeated solution of linear second order partial differential equations (PDE's).

Numerical solution of the synthesis problem. To solve the linear PDE's we assume that the solution can be expanded in normalised bicubic B-spline functions [de Boor (1979)]. The expansion involves a number of sofar unknown coefficients and we now select just as many points, the socalled collocation points. Requiring the series expansion to satisfy the PDE at the collocation points leads to a set of linear equations which upon solution yields the desired coefficients of the expansion. For a detailed description of this procedure, see Viskum (1985). As a result we obtain a continuous expression for the reflector surface.

Analysis of shaped reflectors. Since single, shaped reflectors usually radiates a non-focused beam, the analysis will in general be faster and more accurate when using GTD rather than PO. Thus we have applied the GTD and found that the continuous expression for the surface obtained from the synthesis was a great ad- 
vantage, both for the ray tracing, which is usually the bottleneck in GTD computations, as for the necessary calculation of the differential geometry of the surface. Details of this analysis may also be found in the previously referenced work by Viskum.

Synthesis and analysis of a low orbit shaped beam reflector. The synthesis and analysis techniques outlined above were applied to a particular example, a reflector to provide full earth coverage from a low orbitting satellite. The situation is shown in fig. 2 for an orbit of app. $800 \mathrm{~km}$ above the ground, resulting in a coverage angle of 62.4 degrees. The ideal far-field pattern is shown in fig.3 and the feed pattern is of the form

$$
I(\theta, \phi)=\cos ^{n}(\theta) 00<\theta<100
$$

where $n$ is chosen to provide an edge taper of $10 \mathrm{~dB}$. Note that while the desired far-field pattern is raised towards the edge of coverage, the feed pattern is tapered at the edge of the reflector.

Fig. 4 shows the contour of a rotationally symmetric design. The reflected rays are also indicated, and it is seen that the radiation pattern may be significantly disturbed due to blocking from the feed. Therefore an offset design was made, as shown in fig. 5. Because of the very large coverage area, the offset angle had to be greater than 73 degrees. To emphasize the asymmetry of this design, a contour plot of the reflector is shown in fig. 6 .

Finally, one cut of the radiation pattern is shown in fig. 7 . It follows the ideal pattern shape rather well, although it fails to reproduce the required peak at the edge. This is caused by edge diffraction and may be remedied by modifying the design goal to extend beyond 64.2 degrees and to have a smooth transition instead of the sharp cutoff shown in fig. 3 .

Conclusion. The GO-synthesis problem for single reflectors has been solved numerically by expanding the reflector surface in bicubic spline functions and applying the method of collocation. The solution so obtained was diffraction analysed using the GTD, to which end the representation of the surface was found most convenient. The possibility of designing non-symmetric reflectors has been demonstrated by the application of the synthesis and analysis programmes to a particular reflector configuration.

\section{References}

de Boor, $C$.

"A Practical Guide to Splines". Springer Verlag, N.Y., 1979.

Viskum, H.-H.

"Synthesis and Analysis of Single Shaped Reflector Antennas".

Ph.D. Thesis, Electromagnetics Institute, Techn. Univ. of Denmark, LD 54, 1985.

Westcott, B.S.,

"Shaped Reflector Antenna Design",

Research Studies Press Ltd., UK, 1983. 


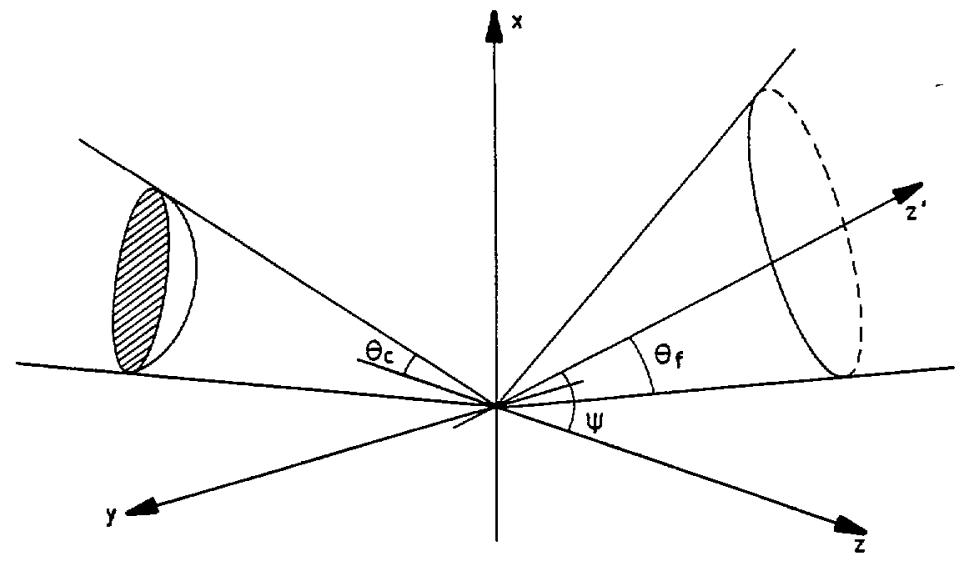

Fig. 1. Coordinate system for the reflector synthesis. The feed is at the centre of the coordinate system and the reflector subtends an angle of ${ }^{2 \theta} \mathrm{c}$. The far-field cone angle is $\theta_{f}$.

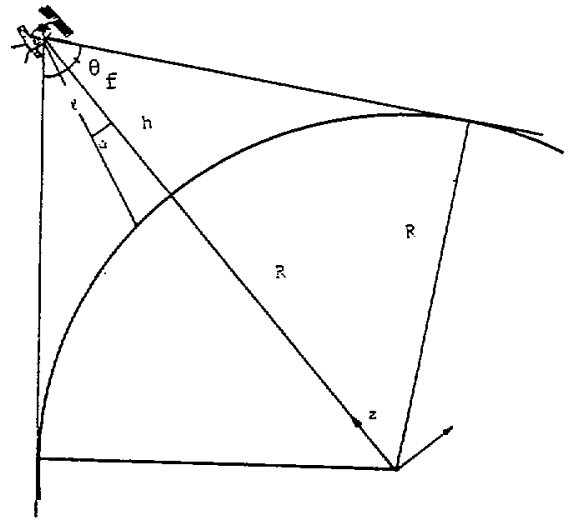

Fig. 2. Geometry for a low orbit satellite. For a height $\mathrm{h}=800 \mathrm{~km}$, $\theta_{f}$ is app. $62.4^{\circ}$.

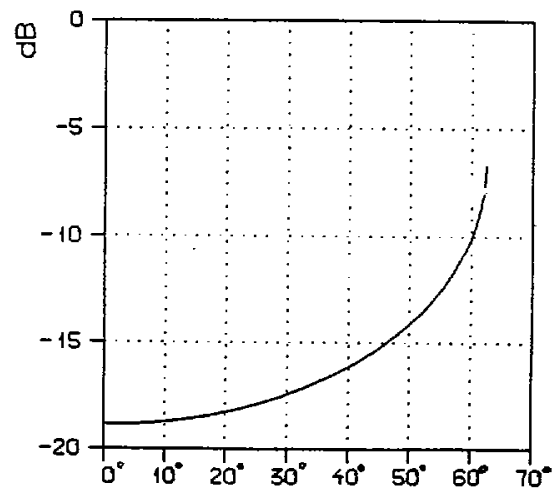

Fig. 3. Ideal pattern shape for the configuration in fig. 2. The absolute level is arbitrary. 


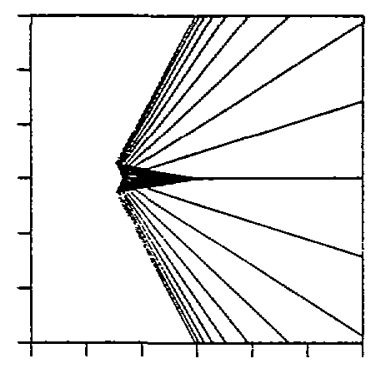

Fig. 4. Reflected rays from a circularly symmetric refletor.

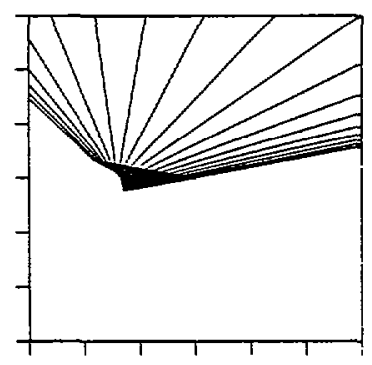

Fig. 5. Offset version of the reflector in fig. 4. Offset angle $=73^{\circ}$.

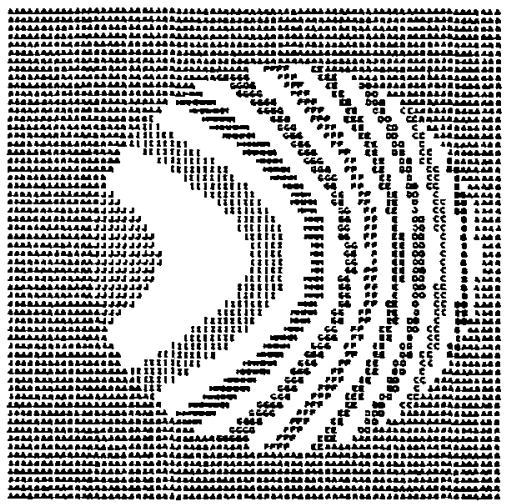

Fig. 6. Contour plot of the reflector in fig. 5 .

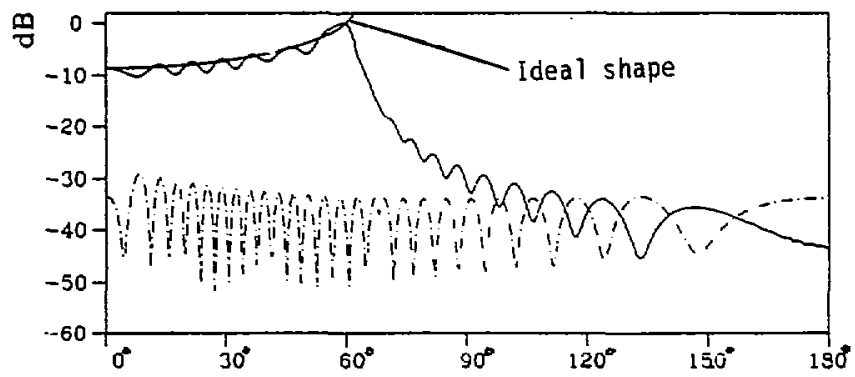

Fig. 7. Radiation pattern for the $73^{\circ}$-offset reflector in the plane orthogonal to the plane of offset. copolar, -..- cross polar.

\section{4}

use limited to: Danmarks Tekniske Informationscenter. Downloaded on July 01,2010 at 08:34:44 UTC from IEEE Xplore. 